TONIOLO, Aline Dip. FRITZ, Karen Beltrame Becker. A adequação da concepção de intitulamentos para a apreciação de dotações e serviços ambientais. Revista Eletrônica Direito e Política, Programa de Pós-Graduação Stricto Sensu em Ciência Jurídica da UNIVALI, Itajaí, v.11, n.1, 10 quadrimestre de 2016. Disponível em: www.univali.br/direitoepolitica - ISSN 1980-7791.

\title{
A ADEQUAÇÃO DA CONCEPÇÃO DE INTITULAMENTOS PARA A APRECIAÇÃO DE DOTAÇÕES E SERVIÇOS AMBIENTAIS
}

\author{
THE SUITABILITY OF ENTITLEMENTS DESIGN FOR ASSESSMENT OF \\ APPROPRIATIONS AND ENVIRONMENTAL SERVICES
}

\section{Karen Beltrame Becker Fritz ${ }^{1}$}

\begin{abstract}
Aline Dip Toniolo ${ }^{2}$
RESUMO

A questão ambiental sempre caracterizou-se como um tema de destaque na literatura econômica, não se restringindo apenas ao direito ambiental, mas integrando o direito econômico, direito comunitário, direito internacional. Diante disso, o hábitat ambiental é o fundamento da vida, razão pela qual mostra imprescindível que os agentes sociais se conscientizem da importância de zelar este bem precioso, para que as futuras gerações possam usufruir de qualidade de vida, visto que se não for contido o esgotamento dos recursos naturais, não haverá equilíbrio vital no planeta. $O$ meio ambiente deve ser tutelado como um direito fundamental do ser humano, visto que consiste em patrimônio da humanidade. Em virtude disso, a natureza não se caracteriza apenas como um recurso produtivo explorado pelos indivíduos detentores do capital e, sim como uma garantia fundamental do ser humano. Diante das diversas interferências humanas no meio ambiente, a teoria econômica passa a preocupar-se com a destruição dos ecossistemas ambientais, dando origem a uma série de alternativas de análise. Neste sentido, entre estas alternativas, destaca-se a abordagem das capacitações elaborada pelo economista indiano Amartya Sen. Em decorrência disso, o empenho analítico visa englobar na análise da realidade social as capacitações. Por conseguinte, uma das percepções gerais que abrangem o sentido analítico é a de intitulamento. Desta maneira, esta pesquisa possui como escopo principal analisar a adequação da concepção de intitulamentos para a apreciação de dotações e serviços ambientais.
\end{abstract}

PALAVRAS-CHAVE: Abordagem das Capacitações. Direito Fundamental. Intitulamento Ambiental. Meio Ambiente.

\footnotetext{
${ }^{1}$ Professora do Programa de Pós-Graduação Mestrado em Direito da Universidade de Passo Fundo (UPF). Doutora em Desenvolvimento Rural pela Faculdade de Ciências Econômicas (FCE) da Universidade Federal do Rio Grande do Sul (UFRGS). Coordenadora da Editora da UPF. karenfritz@upf.br

${ }^{2}$ Advogada. Mestranda do Programa de Pós Graduação do Curso de Direito da UPF - Universidade de Passo Fundo. Graduada em Direito pela Universidade de Passo Fundo (UPF). Bolsista Prosup Capes. Email: alinediptoniolo@gmail.com
} 
TONIOLO, Aline Dip. FRITZ, Karen Beltrame Becker. A adequação da concepção de intitulamentos para a apreciação de dotações e serviços ambientais. Revista Eletrônica Direito e Política, Programa de Pós-Graduação Stricto Sensu em Ciência Jurídica da UNIVALI, Itajaí, v.11, n.1, 10 quadrimestre de 2016. Disponível em: www.univali.br/direitoepolitica - ISSN 1980-7791.

\section{ABSTRACT}

The environmental issue has always been characterized as a prominent issue in the economic literature, not restricted to environmental law, but integrating the economic law, Community law, international law. Thus, the environmental habitat is the foundation of life, which is why shows imperative that social workers are aware of the importance of ensuring this precious commodity, so that future generations can enjoy the quality of life, since it is not contained in the depletion of natural resources, there will be vital balance on the planet. The environment must be protected as a fundamental human right, as consisting of world heritage. As a result, nature is not characterized only as a productive resource exploited by the holders of capital and individuals, but as a fundamental guarantee of the human being. Given the various human interference in the environment, economic theory becomes concerned with the destruction of environmental ecosystems, leading to a series of analysis of alternatives. In this sense, among these alternatives, there is the approach of the capabilities developed by Indian economist Amartya Sen. As a result, the analytical effort intended to cover the analysis of social reality the training. Consequently, the general perception that cover the analytical direction is the intitulamento. Thus, this research has as main purpose to analyze the adequacy of the design of entitlements for consideration of appropriations and environmental services.

KEYWORDS: The Capability Approach. Fundamental Right. Environmental Intitulamento. Environment.

\section{INTRODUÇÃO}

O meio ambiente encontra-se em um processo de exaustão, devido as constantes interferências humanas, na qual os agentes sociais detentores do capital extraem da natureza os recursos naturais sem preocupar-se com os impactos ambientais dessa exploração desenfreada.

Em decorrência disso, presencia-se a ocorrência de acontecimentos catastróficos ambientais no planeta, em razão de haver o esgotamento da disponibilidade destes recursos naturais há muito tempo, em especial pelos países desenvolvidos. Diante disso, a questão ambiental vem sendo uma preocupação para a Ciência Econômica, pois o meio ambiente é um direito fundamental do ser humano. 
TONIOLO, Aline Dip. FRITZ, Karen Beltrame Becker. A adequação da concepção de intitulamentos para a apreciação de dotações e serviços ambientais. Revista Eletrônica Direito e Política, Programa de Pós-Graduação Stricto Sensu em Ciência Jurídica da UNIVALI, Itajaí, v.11, n.1, $1^{\circ}$ quadrimestre de 2016. Disponível em: www.univali.br/direitoepolitica - ISSN 1980-7791.

O meio ambiente é patrimônio da humanidade, possuindo um valor intrínseco enquanto meio de sobrevivência para as presentes e futuras gerações. Em virtude disso, faz-se importante que haja uma mudança de atitudes do grupo social no sentido de preservação deste bem tão precioso para todas as espécies vivas do planeta. Frisa-se que as questões ambientais são assunto de relevância internacional e transnacional, de modo que muitos pesquisadores demonstram insatisfação com as teorias econômicas que versam sobre os problemas ambientais apresentadas pela literatura econômica.

Todavia, para constatar a limitação dos recursos ditos naturais explorados de forma intensa pelos agentes sociais, em especial por se tratar de bens de valoração gratuita, faz-se necessário o uso de um novo arcabouço teórico que verse sobre o desenvolvimento e as questões ambientais. Por esta razão, surge como nova estrutura teórica a Abordagem das Capacitações elaborada pelo economista indiano Amartya Sen.

Objetiva assim, analisar como processa-se a concepção dos intitulamentos com o intuito de avaliar as dotações e os serviços ambientais, de modo que o meio ambiente passa a ser tutelado como um direito fundamental do ser humano, desatrelando-se da ideia de recurso produtivo de exploração. Ainda, visa-se encontrar alternativas para melhorar a condição dos intitulamentos ambientais, já que a partir do intitulamento será possível verificar as capacitações de preferências efetivas que os indivíduos possuem.

Dessa maneira, o intitulamento corrobora para a análise da questão ambiental, contribuindo que a partir do estudo de algumas variáveis possase inquirir sobre como as questões ambientais interferem na qualidade de vida dos seres humanos. Para tanto, a presente pesquisa parte-se do esforço analítico para a análise econômica do problema proposto. Neste sentido, a relevância dessa pesquisa se justifica pelo fato desse tema suscitar a importância do meio ambiente desvencilhar-se da ideia de 
TONIOLO, Aline Dip. FRITZ, Karen Beltrame Becker. A adequação da concepção de intitulamentos para a apreciação de dotações e serviços ambientais. Revista Eletrônica Direito e Política, Programa de Pós-Graduação Stricto Sensu em Ciência Jurídica da UNIVALI, Itajaí, v.11, n.1, $1^{0}$ quadrimestre de 2016. Disponível em: www.univali.br/direitoepolitica - ISSN 1980-7791.

recurso natural a ser explorado e, passa a ser visto como um bem precioso fundamental para a sobrevivência de todas as espécies vivas.

\section{UMA ALTERNATIVA DE ANÁLISE AOS PROCESSOS SOCIAIS DE DESENVOLVIMENTO: A ABORDAGEM DE CAPACITAÇÕES}

A Abordagem das Capacitações foi criada pelo economista indiano Amartya Sen. Essa abordagem consiste em uma alternativa de análise aos processos sociais em desenvolvimento, voltada a questões como a disparidade entre a elevação de recursos financeiros e a constância de problemas como a pobreza e os acontecimentos catastróficos ambientais. Desse modo, a abordagem das capacitações caracteriza-se como uma técnica que visa apontar fundamentos para uma análise do processo de desenvolvimento através de variantes econômicas.

Segundo $\operatorname{Sen}^{3}$, definir o processo de desenvolvimento é um desafio complexo, pois transcende ao atrelamento com o desenvolvimento econômico. O processo de desenvolvimento abrange o desenvolvimento humano, desenvolvimento jurídico, desenvolvimento sustentável, desenvolvimento econômico. Assim, o desenvolvimento representa um prolongamento das liberdades formais e substanciais do ser humano, com o intuito de que os indivíduos possam aperfeiçoar todas as suas potencialidades.

Dessa maneira, o desenvolvimento como propagação de liberdades substantivas dirige-se a finalidades que o evidenciam, ao invés de limita-lo a alguns meios, corroborando para uma importante relevância no processo. Contudo, deixar-se-á para aborda acerca do desenvolvimento como liberdade nos tópicos a seguir, retomando-se, agora, a abordagem das capacitações.

\footnotetext{
${ }^{3}$ SEN, Amartya. O desenvolvimento como liberdade. São Paulo: Companhia das Letras, 1999, p. 125.
} 
TONIOLO, Aline Dip. FRITZ, Karen Beltrame Becker. A adequação da concepção de intitulamentos para a apreciação de dotações e serviços ambientais. Revista Eletrônica Direito e Política, Programa de Pós-Graduação Stricto Sensu em Ciência Jurídica da UNIVALI, Itajaí, v.11, n.1, $1^{\circ}$ quadrimestre de 2016. Disponível em: www.univali.br/direitoepolitica - ISSN 1980-7791.

Primeiramente, a Abordagem das Capacitações consiste em uma alternativa para analisar o desenvolvimento social, o qual se acreditava estar atrelado ao crescimento econômico. Entretanto, surge um grande conflito entre o crescimento econômico e desenvolvimento, pois ocorre o desligamento de duas diretrizes que deram origem a Ciência Econômica, quais sejam: a ética e a engenharia ${ }^{4}$.

Diante da exploração de recursos ditos naturais pelos detentores do capital, a engenharia ocupou lugar de destaque, reduzindo-se a importância da ética, que acabou sendo ignorada, fato que favorece a separação destas duas vertentes em meados do século XVI. Em decorrência disso, presenciou-se a busca desenfreada pela extração de recursos naturais disponíveis no meio ambiente e passa-se a ordenar a produção de bens, sem preocupar-se com o esgotamento de recursos naturais ${ }^{5}$.

Neste sentido, Sen fornece a literatura econômica uma diferenciação entre finalidades e meios, de modo a evidenciar que faz-se necessário que o objeto do processo de desenvolvimento não seja o acúmulo de capital e, sim o bem-estar dos indivíduos ${ }^{6}$. Todavia, esta noção de dissociação do processo de desenvolvimento não se restringiu apenas a Amartya Sen. Esta teoria, também, foi adotada por outros economistas, que observaram a importância do desenvolvimento preocupar-se com a melhoria da qualidade de vida dos cidadãos.

Observa-se, assim, que muitos pesquisadores buscaram tratar a realidade social de uma maneira sucinta, simplificada, ao passo que Sen procurou atentar aos problemas sociais por meio de uma análise multidimensional, acrescentando variantes diversas e focando sua pesquisa além delas. Neste aspecto, constava-se que muitas pessoas sentiam fome, mas o problema

\footnotetext{
${ }^{4}$ SEN, Amartya. 0 desenvolvimento como liberdade. São Paulo: Companhia das Letras, 1999, p. 33.

${ }^{5}$ SEN, Amartya. Desigualdade Reexaminada. Rio de Janeiro: Record. 2001, p. 135.

${ }^{6}$ SEN, Amartya. Desigualdade Reexaminada. Rio de Janeiro: Record. 2001, p. 136.
} 
TONIOLO, Aline Dip. FRITZ, Karen Beltrame Becker. A adequação da concepção de intitulamentos para a apreciação de dotações e serviços ambientais. Revista Eletrônica Direito e Política, Programa de Pós-Graduação Stricto Sensu em Ciência Jurídica da UNIVALI, Itajaí, v.11, n.1, $1^{\circ}$ quadrimestre de 2016. Disponível em: www.univali.br/direitoepolitica - ISSN 1980-7791.

não era a carência de alimentos e, sim a falta de poder aquisitivo destes indivíduos para aquisição de produtos do gênero alimentício.

Entretanto, verifica-se situações de fome por diversas razões: algumas pessoas podem passar fome por não poderem terem condições financeiras de adquirir alimentos, outros indivíduos podem jejuar por motivos religiosos, cidadãos podem ficar sem acesso a alimentos por motivos de desastres ambientais. Logo, há diversas razões para as pessoas ficarem submetidas a situações de fome, o que deve analisar-se são os casos concretos de cada indivíduo, fato que comprova porque Sen defendia a análise multidimensional da realidade social.

Por esta razão, Sen ${ }^{7}$ argumentava que havia um elo entre liberdade dos indivíduos e concretude do desenvolvimento social, transpassando a ideia de uma relação constituída. Diante disso, os que os cidadãos conseguiam fazer positivamente sofria influências de aspectos econômicos, liberdade políticas, fatores educacionais, fatores relacionados a saúde pública. Por isso, a análise seniana preocupava-se em estudar o modo como as pessoas conduziam suas vidas, isto é, como os indivíduos usufruíam de sua liberdade no momento de fazer suas escolhas.

Convém ressaltar que além da definição de liberdade, havia outras noções de conceitos de fundamental importância, entre os quais se destacam: o funcionamento e a capacidade. Conforme Sen, a definição de funcionamento significa:

mais primitiva dentro da abordagem das capacitações e refere-se a 'atividades' [activies] (como ver, comer) ou 'estados de existência' [states of existence or being] (como estar bem nutrido, estar livre de malária, não estar envergonhado pela pobreza da roupa vestida);

\footnotetext{
${ }^{7}$ SEN, Amartya. Sobre ética e economia. São Paulo: Companhia das Letras.1998, p. 55.
} 
TONIOLO, Aline Dip. FRITZ, Karen Beltrame Becker. A adequação da concepção de intitulamentos para a apreciação de dotações e serviços ambientais. Revista Eletrônica Direito e Política, Programa de Pós-Graduação Stricto Sensu em Ciência Jurídica da UNIVALI, Itajaí, v.11, n.1, $1^{0}$ quadrimestre de 2016. Disponível em: www.univali.br/direitoepolitica - ISSN 1980-7791.

por vezes abreviados por 'ações' [doings]e 'estados' [beings]. ${ }^{8}$

Dessa maneira, os funcionamentos consistem em componentes constitutivos da vida pertinentes ao ser humano, ideia esta que dirige a duas atividades de análise. Em virtude disso, é possível afirmar que a primeira atividade analítica relaciona-se a qualidade de bem-estar de uma maneira correlativa a observação da Ciência Econômica, visto que se investiga a aquisição de mercadorias, isto é, analisa-se como os indivíduos têm acesso aos produtos.

A segunda atividade de análise refere-se aos funcionamentos alternativos, levando em consideração o vasto campo de escolhas que os indivíduos tem por optar aos adotar funcionamentos determinados, nascendo um novo dado que não havia ganhado importância até o presente momento. Por conseguinte, partindo destes estados de existência torna-se possível compreender as capacitações do grupo social.

Contudo, estas capacitações que faz-se menção nesta pesquisa diz respeito a capacidade seniana, isto é, a capacitação que determinado indivíduo tem para fazer uma determinada escolha e, não a capacitação da pessoa de fazer algo. Nesta acepção, Sen afirma que:

O conjunto de capacidades representa a liberdade pessoal de realizar várias combinações para a escolha. São todas relevantes para se avaliar o que é vantajoso para uma pessoa, mesmo que ele ou ela, não escolha apenas uma alternativa. Nessa perspectiva, a escolha em si mesma, é uma característica valiosa na vida de uma pessoa 9 .

Diante disso, extrai-se que a capacitação está atrelada ao poder de escolha e a liberdade das pessoas, de modo que os funcionamentos e a capacitação

\footnotetext{
${ }^{8}$ SEN, Amartya. Desigualdade Reexaminada. Rio de Janeiro: Record. 2001, p. 236.

${ }^{9}$ SEN, Amartya. O desenvolvimento como expansão das capacitações. Lua Nova: Revista de Cultura e Política. N. 28. São Paulo:CEDEC. 1993, p. 324.
} 
TONIOLO, Aline Dip. FRITZ, Karen Beltrame Becker. A adequação da concepção de intitulamentos para a apreciação de dotações e serviços ambientais. Revista Eletrônica Direito e Política, Programa de Pós-Graduação Stricto Sensu em Ciência Jurídica da UNIVALI, Itajaí, v.11, n.1, $1^{0}$ quadrimestre de 2016. Disponível em: www.univali.br/direitoepolitica - ISSN 1980-7791.

dão origem a informações, porém possuem espaços distintos. Nesta sequência, deve-se ter me mente que conhecer o gosto de um grupo de indivíduos não significa que se tenha ciência das capacitações que aquelas pessoas possuem.

Para maior elucidação da capacitação que os cidadãos apresentam, em especial em países subdesenvolvidos, que possuem grande parcela de sua população em situação de pobreza, desprovidos de condições mínimas de subsistência, sujeitos a carência de alimentos, torna-se uma tarefa complexa a análise de possibilidades. Em virtude disso, origina-se a noção de intitulamentos, decorrente da abordagem desenvolvida por Sen. Dessa forma, por meio dos intitulamentos propõem-se observar como os indivíduos tem acesso a bens e serviços e como são asseguradas as suas garantias e deveres perante a lei.

Convém ressaltar que a ideia de intitulamento emergiu-se diante da necessidade de analisar o problema social da carência alimentar, drama enfrentado por milhares de pessoas em diversas partes do planeta. Nesta acepção, Sen aponta que:

\begin{abstract}
A abordagem da carência alimentar e das fomes em termos de concessãode direitos concentra-se na capacidade de as pessoas disporem dos alimentos através dos meios legais disponíveis na sociedade, incluindo a utilização de possibilidades de produção e de oportunidades comerciais, de direitos e relação ao Estado e de outros métodos de aquisição de alimentos. Uma pessoa morre de fome ou porque não tem capacidade de dispor de alimentos suficientes, ou porque não utiliza essa capacidade para evitar a carência alimentar. A abordagem em termos de intitulamentos concentra-se na primeira possibilidade, ignorando a última. ${ }^{10}$
\end{abstract}

Entretanto, o intitulamento não se limitou apenas a estudar apenas o problema da fome, analisando, também, a estrutura de bens e serviços em

\footnotetext{
${ }^{10}$ SEN, Amartya. Sobre ética e economia. São Paulo: Companhia das Letras.1998, p. 71.
} 
TONIOLO, Aline Dip. FRITZ, Karen Beltrame Becker. A adequação da concepção de intitulamentos para a apreciação de dotações e serviços ambientais. Revista Eletrônica Direito e Política, Programa de Pós-Graduação Stricto Sensu em Ciência Jurídica da UNIVALI, Itajaí, v.11, n.1, $1^{\circ}$ quadrimestre de 2016. Disponível em: www.univali.br/direitoepolitica - ISSN 1980-7791.

sentido latu sensu. Assim, a partir da noção de intitulamentos é possível verificar que a situação de fome enfrentada por uma parcela da população não se deve a disponibilidade de produtos do gênero alimentícios, mas a carência de oportunidade destes indivíduos de adquirirem estes produtos. Consequentemente, observa-se que não há carência de alimentos e, sim oportunidades para os indivíduos apropriarem-se de alimentos. Sen ${ }^{11}$ entende que a ausência de intitulamentos corrobora para imperfeições nas capacidades ou, ainda, uma estagnação na capacitação dos indivíduos.

Dessa maneira, a produção de alimentos em elevadas quantidades não é o objeto de análise e, sim a ideia de oportunidade de escolhas que as pessoas têm acesso que define o principal papel dos intitulamentos. Neste sentido, a investigação de políticas públicas pode ser a ferramenta mais apropriada para examinar a questão da apropriação de produtos e serviços ambientais, visando modificar a concepção de acesso a oportunidades que possuem os agentes sociais.

Importa perquirir que os intitulamentos sofrem diversas interferências, encontrando-se atrelados à ideia de dotação, que se refere à concepção dos recursos valoráveis à humanidade, como a disponibilidade de recurso hídricos no planeta. Em seguida, o intitulamento é persuadido pelas oportunidades de produção. Esta interferência diz respeito aos meios tecnológicos disponíveis para criar as condições concretas da sustentação analisada e da acessibilidade de conhecimento ao acesso para usufruir destas condições ${ }^{12}$. Conforme entendimento de Sen,

No mundo todo, a maioria das pessoas não produz alimentos diretamente; elas ganham seu potencial para adquirir alimentos empregando-se na produção de outras mercadorias, as quais podem variar de culturas agrícolas comerciais a produtos artesanais, artigos

\footnotetext{
${ }^{11}$ SEN, Amartya. Desigualdade Reexaminada. Rio de Janeiro: Record. 2001, p. 42.

12 SEN, Amartya. O desenvolvimento como liberdade. São Paulo: Companhia das Letras, 1999, p. 189.
} 
TONIOLO, Aline Dip. FRITZ, Karen Beltrame Becker. A adequação da concepção de intitulamentos para a apreciação de dotações e serviços ambientais. Revista Eletrônica Direito e Política, Programa de Pós-Graduação Stricto Sensu em Ciência Jurídica da UNIVALI, Itajaí, v.11, n.1, $1^{\circ}$ quadrimestre de 2016. Disponível em: www.univali.br/direitoepolitica - ISSN 1980-7791.

industrializados e serviços diversos, envolvendo uma variedade de ocupações ${ }^{13}$.

Desse modo, a dotação e as capacitações de produção podem demonstrar se há um intitulamento específico na realidade social. Por conseguinte, os intitulamentos evidenciam vínculos entre eventos estruturais que corroborariam para a elevação das capacitações. Ainda, a análise de intitulamento poderia demonstrar que a ausência de possibilidade dos indivíduos terem acesso a bens e serviços, inibiria oportunidades, restringindo as capacitações.

Nesta acepção, diante da abordagem seniana acerca das capacitações e, consequentemente da inobservância de algumas garantias fundamentais aos seres humanos, nasce à preocupação de pesquisadores sociais em relacionarem a abordagem das capacitações e as questões ambientais. No entanto, como há uma distorção entre crescimento econômico e a noção de desenvolvimento, pois ocorre o meio ambiente vêm sendo explorado e os agentes sociais detentores do capital ${ }^{14}$.

Assim, os recursos naturais estão sendo apropriados de maneira exaustiva e, consequentemente a natureza vem sofrendo um acelerado processo de devastação, visto que a perdura a ideia de que os recursos naturais devem ser comercializados. Por sua vez, esta noção de que tudo o que advém do meio ambiente deve ser comercializado, acaba resultando na redução da capacidade dos seres humanos. Diante disso, no tópico a seguir, abordarse-á o meio ambiente como um direito fundamental do ser humano e a necessidade de tutela-lo, como um intitulamento apto a promover a expansão das capacitação humanas.

13 SEN, Amartya. O desenvolvimento como liberdade. São Paulo: Companhia das Letras, 1999, p. 191.

${ }^{14}$ SEN, Amartya. 0 desenvolvimento como liberdade. São Paulo: Companhia das Letras, 1999, p. 195. 
TONIOLO, Aline Dip. FRITZ, Karen Beltrame Becker. A adequação da concepção de intitulamentos para a apreciação de dotações e serviços ambientais. Revista Eletrônica Direito e Política, Programa de Pós-Graduação Stricto Sensu em Ciência Jurídica da UNIVALI, Itajaí, v.11, n.1, 10 quadrimestre de 2016. Disponível em: www.univali.br/direitoepolitica - ISSN 1980-7791.

\section{O MEIO AMBIENTE COMO DIREITO FUNDAMENTAL DO SER}

\section{HUMANO}

O meio ambiente vêm enfrentando diversas transformações, devido à exploração de seus recursos naturais de forma depredatória e itinerante pelos agentes sociais. A exploração de recursos naturais pelo ser humano está intimamente relacionada à modernidade. Nas palavras de Harvey ${ }^{15}$, os indivíduos passam por variadas adversidades $e$, isto reflete nas diversas experiências vitais. Esse aglomerado de adversidades e experiência denomina-se modernidade.

A noção de progresso tecnológico, de modificações no meio ambiente, crescimento econômico, desenvolvimento humano, a busca pela alegria e lazer, situam-se na modernidade. Todavia, o mundo moderno pode eliminar tudo o que se tem, pois se os recursos hídricos não forem utilizados de forma sustentável, por exemplo, a população que tem acesso a esse bem ficará sem água potável para consumir.

Ao passo que a modernidade conecta os seres humanos, ultrapassando todos os limites fronteiriços, sejam no tocante a ideologias, fatores geográficos, religiosos, étnicos. Entretanto, a modernidade traz consigo aspectos negativos, o que possibilita afirmar que a modernidade é ambivalente. Assim, a modernidade vincula-se no cotidiano dos seres humanos, razão pela qual Harvey, ilustra que "a modernidade, por conseguinte, não apenas envolve uma implacável ruptura com todas e quaisquer condições históricas precedentes, como é caracterizada por um interminável processo de rupturas e fragmentações internas inerentes"16.

Contudo, o meio ambiente é atingido pelos efeitos da globalização, que caracteriza-se como um fenômeno mundial que influencia a realidade social. Neste sentido, a globalização avoca consigo o capitalismo, que é uma etapa

\footnotetext{
${ }^{15}$ HARVEY, David. Condição Pós- Moderna. 5. ed. São Paulo: Loyola, 1992, p. 49.

${ }^{16}$ HARVEY, David. Condição Pós- Moderna. 5. ed. São Paulo: Loyola, 1992, p. 52.
} 
TONIOLO, Aline Dip. FRITZ, Karen Beltrame Becker. A adequação da concepção de intitulamentos para a apreciação de dotações e serviços ambientais. Revista Eletrônica Direito e Política, Programa de Pós-Graduação Stricto Sensu em Ciência Jurídica da UNIVALI, Itajaí, v.11, n.1, $1^{\circ}$ quadrimestre de 2016. Disponível em: www.univali.br/direitoepolitica - ISSN 1980-7791.

que interfere na produção de bens e serviços. Assim sendo, a globalização intromete-se em todos os setores sociais, desde as esferas econômicas, políticas e, consequentemente a esfera ambiental ${ }^{17}$.

Nos dias atuais, os problemas ambientais constituem-se como uma preocupação de toda a sociedade, visto que o meio ambiente é patrimônio da humanidade, sendo um direito transnacional. Essa atenção ao meio ambiente têm ganho destaque devido a sinais que a natureza tem dado acerca da exaustão de seus recursos naturais. Diante da importância do meio ambiente para os seres humanos, faz-se necessário apontar algumas considerações acerca de sua abrangência de sua delimitação conceitual.

Inicialmente, a definição de meio ambiente pode ser encontrada na Lei da Política Nacional do Meio Ambiente, da qual se extrai por meio do art. 30 , inciso I: "meio ambiente, o conjunto de condições, leis, influencias e interações de ordem física, química e biológica, que permite, abriga e rege a vida em todas as suas formas" ${ }^{18}$.

Já na Constituição Federal, a conceituação de meio ambiente volta-se a perspectiva humana e social, elevando o meio ambiente ao status de direito fundamental do ser humano, almejando a proteção do habitat ambiental. No entanto, a repercussão com as questões ambientais ganham destaque a partir da Conferência das Nações Unidas, realizada em junho de 1972, em Estocolmo, onde o meio ambiental foi declarado como um direito fundamental do ser humano, através da Declaração do Meio Ambiente, nela contendo-se os 26 princípios que configuram-se como uma continuidade da Declaração Universal dos Direitos do Homem.

\footnotetext{
${ }^{17}$ IANNI, Octavio. A era do globalismo. 5. ed. - Rio de Janeiro: Civilização Brasileira, 2001, p. 24.

18 BRASIL, Vade Mecum Saraiva: obra coletiva de autoria da Editora Saraiva com a colaboração de Luiz Roberto Curia, Livia Céspedes e Juliana Nicoletti. 6. ed. atual. e ampl. São Paulo: Saraiva, 2014, p. 1397.
} 
TONIOLO, Aline Dip. FRITZ, Karen Beltrame Becker. A adequação da concepção de intitulamentos para a apreciação de dotações e serviços ambientais. Revista Eletrônica Direito e Política, Programa de Pós-Graduação Stricto Sensu em Ciência Jurídica da UNIVALI, Itajaí, v.11, n.1, 10 quadrimestre de 2016. Disponível em: www.univali.br/direitoepolitica - ISSN 1980-7791.

Por conseguinte, após a Conferência de Estocolmo alça-se o meio ambiente a categoria de direito fundamental do homem e requisito imprescindível para a qualidade de vida no planeta. Em sequência, houveram outros episódios que preconizaram a conscientização da sociedade para a proteção ambiental, tais como a Rio +20 e o Protocolo de Quioto, que intervinham em prol do desenvolvimento sustentável e da preservação da diversidade biológica.

A tutela ambiental passou a destacar no Brasil por meio da Constituição Federal de 1988, apresentando vários dispositivos legais que previam obrigações aos agentes sociais, com o intuito de zelar e preservar o meio ambiente, espaço vital da humanidade. Dessa maneira, a Magna Carta propiciou muitos progressos na esfera ambiental trazendo maior segurança jurídica a este bem tão precioso denominado meio ambiente

Entretanto, para ser resguardado o hábitat ambiental faz-se necessário o empenho de imposições legais para coibir os constantes desmatamentos, tráfico de animais silvestres, práticas de biopirataria, exploração desenfreada de recursos naturais, almejando preservar o meio ambiente. Em vista disso, se não houver mudança na atitude dos agentes sociais a sobrevivência das espécies vivas restará ameaçada.

O grupo social convive com diversos acontecimentos ambientais catastróficos, resultado de danos irreparáveis causados pelo homem à natureza. Conforme Alvarenga ${ }^{19}$, a agressão ao meio ambiental comina perigo, pois as implicações dos danos ambientais são observadas nas modificações climáticas, como nas fortes enchentes que assolaram o sul do Brasil no mês de julho do ano de 2015.

Neste seguimento, constata-se a fragilidade humana perante as intempéries ambientais, porém o ser humano continua a devastar o meio ambiente, extraindo da natureza seus recursos, vendo-os como bens comercializáveis.

19 ALVARENGA, Paulo. Proteção jurídica do meio ambiente. São Paulo: Lemos e Cruz, 2005, p. 45. 
TONIOLO, Aline Dip. FRITZ, Karen Beltrame Becker. A adequação da concepção de intitulamentos para a apreciação de dotações e serviços ambientais. Revista Eletrônica Direito e Política, Programa de Pós-Graduação Stricto Sensu em Ciência Jurídica da UNIVALI, Itajaí, v.11, n.1, $1^{\circ}$ quadrimestre de 2016. Disponível em: www.univali.br/direitoepolitica - ISSN 1980-7791.

Isto é reflexo da globalização e da modernidade, que favoreceram a expansão dos mercados de produção e influenciaram a economia mundial.

Todavia, esta ampliação da economia mundial exige elevados investimentos nos setores tecnológicos, por exemplo, para produzir efeitos gratificantes, 0 que acarreta resultados ambivalentes e deve ser revertido em prol do meio ambiente. É inegável que a modernidade traga vantagens à humanidade, porém se esta mesma modernidade não apresentar soluções para proteger o meio ambiente e a sociedade não se conscientizar da importância da tutela ambiental, todas as espécies vivas do planeta estarão com a sua sobrevivência ameaçada ${ }^{20}$.

Evidencia-se com a expansão da economia, o nascimento de novos direitos e garantias fundamentais, visando compatibilizar os seres humanos entre si e com o local onde vivem. Consequentemente, há uma primeira dimensão de direitos e garantias fundamentais do ser humano, o qual engloba os direitos de liberdade; uma segunda dimensão que abrange os direitos sociais, uma terceira dimensão que envolve os direitos ambientais. Para fins desta pesquisa, citar-se-á até a terceira geração de direitos fundamentais, visto haver controvérsias no tocante às gerações de direitos fundamentais, havendo doutrinadores que apontam existir mais gerações de direitos fundamentais ${ }^{21}$. Como anteriormente mencionado, o meio ambiente é um direito fundamental do ser humano, estando intimamente vinculado ao Princípio da Dignidade da Pessoa Humana. À vista disso, torna-se impossível haver dignidade se não é assegurado aos indivíduos um ambiente saudável, equilibrado e em harmonia. Sem embargo, para que haja um meio ambiente sadio faz-se imprescindível que os ecossistemas ambientais sejam tutelados e preservados. Assim, Sarlet entende que:

20 RATTNER, Henrique. Liderança para uma sociedade sustentável. São Paulo: Nobel, 1999, p. 29.

${ }^{21}$ FERNANDES, Márcio Borba. Termo de ajustamento de conduta ambiental e seus efeitos na responsabilização penal. In Temas Críticos em Direito. Organizadores: Alberto Wunderlich... [et al]. Guaiba: Sob Medida, 2012. v. 2., p. 46. 
TONIOLO, Aline Dip. FRITZ, Karen Beltrame Becker. A adequação da concepção de intitulamentos para a apreciação de dotações e serviços ambientais. Revista Eletrônica Direito e Política, Programa de Pós-Graduação Stricto Sensu em Ciência Jurídica da UNIVALI, Itajaí, v.11, n.1, $1^{\circ}$ quadrimestre de 2016. Disponível em: www.univali.br/direitoepolitica - ISSN 1980-7791.

[...] sempre haverá como sustentar a dignidade da própria vida de um modo geral, ainda mais numa época em que o reconhecimento da proteção ao meio ambiente como valor fundamental indica que não mais está em causa apenas a vida humana, mas a preservação de todos os recursos naturais, incluindo todas as formas de vida existentes no planeta, ainda que se possa argumentar que tal proteção da vida em geral constitua, em ultima análise, exigência da vida humana e vida humana com dignidade ${ }^{22}$.

Além disso, faz-se relevante que os indivíduos habitem um ambiente sadio, que Ihes possibilite atender a critérios mínimos de dignidade, para que seja possível aos seres humanos desenvolverem suas capacitações e não retêlas. Ainda, se não for protegido o meio ambiente, o planeta tornar-se-á um local inóspito às futuras gerações. Observa-se, para tanto, que institui-se como fundamental que os agentes sociais colaborem com a tutela ambiental, erigindo políticas públicas voltadas a tutela da natureza.

Conforme o texto constitucional brasileiro, extrai-se ser incumbência dos agentes sociais a tutela ambiental, sendo que o artigo 225, caput, aponta como ônus do Poder Público a defesa do meio ambiente. Importante contribuição traz Sirvinskas ao afirmar que:

Assim, em matéria de meio ambiente, compete ao Poder Público a responsabilidade de dar efetividade ao princípio matriz contido no caput do art. 225 da Constituição Federal. Para a sua implementação são necessários instrumentos políticos, legais, técnicos e econômicos colocados à disposição do Poder Público com a finalidade de cumprir esse objetivo maior. Assim, o meio ambiente ecologicamente equilibrado é um direito de todos, portanto, a responsabilidade de

22 SARLET, Ingo Wolfgang. Dignidade da pessoa humana e direitos fundamentais na Constituição Federal de 1988. 2. ed. rev. amp. - Porto Alegre: Livraria do Advogado, 2002, p. 35. 
TONIOLO, Aline Dip. FRITZ, Karen Beltrame Becker. A adequação da concepção de intitulamentos para a apreciação de dotações e serviços ambientais. Revista Eletrônica Direito e Política, Programa de Pós-Graduação Stricto Sensu em Ciência Jurídica da UNIVALI, Itajaí, v.11, n.1, $1^{\circ}$ quadrimestre de 2016. Disponível em: www.univali.br/direitoepolitica - ISSN 1980-7791.

preservá-lo e defende-lo deve ser também compartilhada com a comunidade ${ }^{23}$.

Assim, resta evidente a responsabilidade compartilhada dos indivíduos e do Poder Público de tutelar o meio ambiente, para que se iniba a devastação ambiental que ocorre em ritmo acelerado, em razão da noção de que o meio ambiente pode ter seus recursos naturais explorados $e$ comercializados. Diante disso, demostra-se ser determinante a conscientização de que o meio ambiente é um direito do cidadão e, elemento de suma relevância para o desenvolvimento das capacitações dos indivíduos.

Logo, as questões ambientais merecem toda a atenção por constituírem-se pelo fato dos ecossistemas ambientais fornecerem as condições mínimas existenciais de sobrevivência no planeta. Segundo o entendimento de Ferrer,

La Humanidad, al menos de momento, tiene que conformarse con lo que tiene, porque no hay nada más allá. Esta noción es tan elemental como rigurosamente nueva en la historia del Hombre y le obliga a trascendentales cambios conceptuales ${ }^{24}$.

Os desastres ambientais contribuem para a situação de fome enfrentada por muitos indivíduos e, não apenas as dificuldades de acesso a aquisição de produtos alimentícios, jejuns, pois as enchentes, furacões destroem plantações. Ora, as situações de fome não ocorrem devido à carência de alimentos, só que podem ser presenciadas ausência de produtos alimentícios motivados por alterações climáticas decorrentes de danos ambientais irreparáveis.

23 SIRVINSKAS, Luís Paulo. Manual de direito ambiental. 7. ed. rev. atual. e ampl. São Paulo: Saraiva, 2009, p. 113.

${ }^{24}$ FERRER, Gabriel Real. La construcción del Derecho Ambiental. Revista Aranzadi de Derecho Ambiental (Pamplona, España), no 1, 2002, p. 73-93. 
TONIOLO, Aline Dip. FRITZ, Karen Beltrame Becker. A adequação da concepção de intitulamentos para a apreciação de dotações e serviços ambientais. Revista Eletrônica Direito e Política, Programa de Pós-Graduação Stricto Sensu em Ciência Jurídica da UNIVALI, Itajaí, v.11, n.1, $1^{\circ}$ quadrimestre de 2016. Disponível em: www.univali.br/direitoepolitica - ISSN 1980-7791.

Neste sentido, ressalta-se que os problemas ambientais estão intimamente relacionados com a realidade social e, por conseguinte, o meio ambiente merece muita proteção e atenção por parte dos agentes sociais, visto que ele interfere na capacidade de escolhas e na qualidade de vida das pessoas. Desta maneira, verifica-se que o meio ambiente é um direito fundamental do ser humano e, encontra-se atrelado a Dignidade da Pessoa Humana.

O texto constitucional elucida no seu artigo $1^{0}$, III, a Dignidade da Pessoa Humana como uma garantia fundamental do ser humano, visto que a partir dos recursos fornecidos pelo meio ambiente o homem deleita suas necessidades. Nesta continuidade, um meio ambiente sadio corrobora para que os indivíduos vivam em condições dignas. Além disso, os problemas ambientais ultrapassam fronteiras nacionais, que somente através de uma mudança de atitudes por parte dos agentes sociais poder-se-á reverter esta degradação ambiental e inibir novos danos ambientais. Desse modo, Cruz ensina que:

[...] Estas ameaças decorrem do esgotamento dos recursos naturais não renováveis, da falta de distribuição equitativa dos bens ambientais, do crescimento exponencial da população, da pobreza em grande escala e do surgimento de novos processos tecnológicos excludentes do modelo capitalista. Todos estes fatores contribuem com a consolidação de uma ética individualista e desinteressada com o outro, com o distante, com as futuras gerações e com um desenvolvimento sustentável. Este quadro desafiante impõe a necessidade não apenas de ações locais e isoladas, mas de uma especial sensibilização também globalizada, que contribua com a internalização de novas práticas e atitudes, principalmente nas ações dos Estados. Só com a criação de um Estado Transnacional Ambiental é que será possível a construção um compromisso solidário e global em prol do Ambiente, para que seja assegurada de maneira preventiva e precautória a melhora contínua das relações entre o homem e a natureza ${ }^{25}$.

${ }^{25}$ CRUZ, Paulo Márcio. Da soberania à transnacionalidade: democracia, direito e estado no século XXI. Itajaí: Universidade do Vale do Itajaí, 2011, p. 154/155. 
TONIOLO, Aline Dip. FRITZ, Karen Beltrame Becker. A adequação da concepção de intitulamentos para a apreciação de dotações e serviços ambientais. Revista Eletrônica Direito e Política, Programa de Pós-Graduação Stricto Sensu em Ciência Jurídica da UNIVALI, Itajaí, v.11, n.1, 10 quadrimestre de 2016. Disponível em: www.univali.br/direitoepolitica - ISSN 1980-7791.

Neste aspecto, constata-se a importância dos agentes sociais se conscientizarem de que a natureza é uma instituição que caminha rumo a falência, pois seus recursos estão sendo apropriados pelo ser humano de forma avassaladora, como se seus recursos naturais fossem infindáveis, ilimitados, o que de fato não é verídico e o homem precisa minimizar a destruição ambiental, para não presenciar sua própria extinção perante suas atitudes consumeristas.

É inegável que a modernidade e a globalização, como anteriormente mencionadas, transformam a realidade social, pois interferem nas expectativas de vida, nas capacitações de escolhas do indivíduo. Todavia, os seres humanos devem clarificar-se que a qualidade de vida não está atrelada a elevação da aquisição de bens e serviços, na observância das condições mínimas existenciais de dignidade.

Nesta acepção, percebe-se aspectos ambíguos, pois ao passo que há uma parcela de indivíduos que usufruem de bens e serviços com extrema facilidade, fazendo uso de recursos ditos naturais imaginando serem infindáveis, há uma parcela da população que não tem acesso a aquisição destes mesmos bens e serviços por motivos diversos. Por esta razão, que a análise seniana aponta que a realidade social deve ser analisada de forma multidimensional $^{26}$.

Assim, a ciência econômica vinculada a ações de cunho social voltam-se a efetivação do desenvolvimento como caminho para a proteção dos ecossistemas ambientais. Neste seguimento, pesquisadores naturais e sociólogos necessitam laborar unidos, com o intuito de encontrar soluções para o uso consciente e aproveitamento dos recursos extraídos da natureza. Consequentemente, a exploração moderada destes recursos ambientais irá evitar a extinção da biodiversidade existente, porém faz-se necessário que

${ }^{26}$ SEN, Amartya. O desenvolvimento como liberdade. São Paulo: Companhia das Letras, 1999, p. 35. 
TONIOLO, Aline Dip. FRITZ, Karen Beltrame Becker. A adequação da concepção de intitulamentos para a apreciação de dotações e serviços ambientais. Revista Eletrônica Direito e Política, Programa de Pós-Graduação Stricto Sensu em Ciência Jurídica da UNIVALI, Itajaí, v.11, n.1, $1^{\circ}$ quadrimestre de 2016. Disponível em: www.univali.br/direitoepolitica - ISSN 1980-7791.

as atitudes humanas sejam transformadas, voltando-se a tutela ambiental e ao uso sustentável dos recursos naturais ${ }^{27}$.

Além disso, os avanços econômicos, tecnológicos estão atrelados ao processo de desenvolvimento. Aliás, a própria evolução humana caracteriza-se como um requisito de suma relevância para o processo financeiro, social, politico o qual abrange o ser humano, favorecendo o bem-estar dos agentes sociais, porém este progresso humano deve dirigirse a tutela ambiental, porque é possível haver desenvolvimento e preservação ambiental ${ }^{28}$.

Diante do exposto, após abordar o meio ambiente como um direito fundamental do ser humano, passa-se a expor sobre a significância de tratar o meio ambiente como um intitulamento que propicia o desenvolvimento das capacitações individuais dos seres humanos.

\section{O INTITULAMENTO AMBIENTAL COMO INSTRUMENTO PARA A CAPACITAÇÃO DAS PESSOAS}

O meio ambiente é um direito fundamental do ser humano, bem precioso que satisfaz todas as necessidades do ser humano. No entanto, o meio ambiente possui uma definição fundamental que deve ser contida que é a dotação, designação intimamente relacionada aos intitulamentos. Nas palavras de Sen, extrai-se:

\footnotetext{
${ }^{27}$ MILARÉ, Édis. Direito do ambiente. 7. ed. São Paulo: Editora Revista dos Tribunais, 2012, p. 91.

28 DIAFÉRIA, Adriana. Desenvolvimento sustentável e o direito ao progresso científico, tecnológico e econômico: as oportunidades e as possibilidades de tutela. Meio ambiente, direito e biotecnologia: estudos em homenagem ao Prof. Dr. Paulo Affonso Leme Machado. Maria Auxiliadora Minahim, Tiago Batista Freitas, Thiago Pires Oliveira (coords.) Curitiba: Juruá, 2010, p. 447.
} 
TONIOLO, Aline Dip. FRITZ, Karen Beltrame Becker. A adequação da concepção de intitulamentos para a apreciação de dotações e serviços ambientais. Revista Eletrônica Direito e Política, Programa de Pós-Graduação Stricto Sensu em Ciência Jurídica da UNIVALI, Itajaí, v.11, n.1, $1^{\circ}$ quadrimestre de 2016. Disponível em: www.univali.br/direitoepolitica - ISSN 1980-7791.

In a economy with private ownership and exchange in the form of trade (exchange with others) and production (exchange with nature), $\mathrm{Ei}$ can be characterized as depending on two parameters: the endowment vector $\mathrm{x}$ and an exchange entitlement mapping $\mathrm{Ei}($.$) , which person i can choose to have$ through 'exchange' (trade and production) ${ }^{29}$.

Segundo os ensinamentos de Hodgson verifica-se que a noção de dotação refere-se às garantias e recursos que os agentes sociais possuem. Fazem parte destes recursos e garantias: a terra, o ar, atividades laborais, as habilidades individuais, concepção diversa do conceito de intitulamento ambiental. Por outro lado, a definição de intitulamento ambiental diz respeito ao agrupamento de utilidades decorrentes dos bens e serviços ambientais, dos quais os indivíduos apresentam reais oportunidades de escolha e os quais operacionalizam para o bem-estar dos agentes sociais ${ }^{30}$.

Assim, como intitulamentos ambientais citam-se: os alimentos, os recursos naturais, os recursos hídricos, as fontes de energia, além de outras atividades de cunho ambiental, sempre lembrando que os intitulamentos intensificam as capacitações dos seres humanos. Contudo, cabe perquirir que os intitulamentos e as dotações estão intimamente relacionados, de modo que as dotações só atingem a sua finalidade quando englobam os intitulamentos. Desse modo, é possível afirmar que os intitulamentos expandem a capacidade das pessoas de fazerem suas escolhas ${ }^{31}$.

Em sentido ambiental, distinguir dotações e intitulamentos torna-se essencialmente importante. Neste sentido, os bens e serviços ambientais apenas cumprem seu papel utilitário quando refletem na qualidade de vida

\footnotetext{
${ }^{29}$ SEN, Amartya. Ingredients of famine analysis: availability and entitlements. The Quarterly Journal of Economics, Aug, 1981. p. 435.

30 HODGSON, Geoffrey. The hidden persuaders: institutions and individuals in economic theory. Cambridge Journal of Economics, n. 27, 2003, p. 161.

${ }^{31}$ SEN, Amartya. Ingredients of famine analysis: availability and entitlements. The Quarterly Journal of Economics, Aug, 1981, p. 444.
} 
TONIOLO, Aline Dip. FRITZ, Karen Beltrame Becker. A adequação da concepção de intitulamentos para a apreciação de dotações e serviços ambientais. Revista Eletrônica Direito e Política, Programa de Pós-Graduação Stricto Sensu em Ciência Jurídica da UNIVALI, Itajaí, v.11, n.1, $1^{\circ}$ quadrimestre de 2016. Disponível em: www.univali.br/direitoepolitica - ISSN 1980-7791.

e bem-estar dos indivíduos, ao passo que exercem oportunidades de escolhas sobre eles.

Dessa maneira, os bens e serviços ambientais por meio de uma intervenção realizada pelas dotações e intitulamentos, desenvolvem e expandem a capacidade das pessoas. Neste aspecto, é possível afirmar que um bem ambiental apenas se configura como um intitulamento quando melhora a qualidade de vida de um indivíduo, caso contrário, não é possível enquadralo como um intitulamento.

Neste ângulo, uma grande extensão de terra se não for produtiva, não produzindo alimentos ou oferecendo ao seu proprietário qualquer tipo de renda, de modo a não contribuir para o bem-estar dos agentes sociais, não configura um intitulamento. Entretanto, cabe lembrar que o intitulamento não está vinculado ao ganho econômico, a aquisição de recursos financeiros e, sim a melhoria na qualidade de vida das pessoas.

Em consequência disso, a dotação ambiental somente é transformada em intitulamento, quando produz satisfação, alegria, bem-estar aos indivíduos, se refletindo em melhoria das condições de vida e propiciando as pessoas expandirem suas capacitações através de suas escolhas. Desse modo, se os indivíduos não conseguir usufruírem de determinadas dotações, não se presencia um intitulamento.

Segundo os apontamentos de Sen, a capacidade dos agentes sociais elevase, expandindo as oportunidades de escolha. Consequentemente, cria-se um quadro dependente e repentino, isto é, um círculo vicioso, de modo que cada vez que as pessoas expandem suas capacitações, há um aumento de suas possibilidades de escolha. Isso, corrobora para a formação de novas liberdades ${ }^{32}$.

\footnotetext{
${ }^{32}$ SEN, Amartya. O desenvolvimento como expansão das capacitações. Lua Nova: Revista de Cultura e Política. N. 28. São Paulo:CEDEC. 1993, p. 45.
} 
TONIOLO, Aline Dip. FRITZ, Karen Beltrame Becker. A adequação da concepção de intitulamentos para a apreciação de dotações e serviços ambientais. Revista Eletrônica Direito e Política, Programa de Pós-Graduação Stricto Sensu em Ciência Jurídica da UNIVALI, Itajaí, v.11, n.1, $1^{0}$ quadrimestre de 2016. Disponível em: www.univali.br/direitoepolitica - ISSN 1980-7791.

Conforme Zanin, "o ranking global dos quase 900 milhões de famintos, contrapõe-se à marca de 1,6 bilhão de toneladas de gêneros comestíveis perdidos e hipoteticamente suficientes para alimentar dois bilhões de pessoas" $^{\prime \prime 3}$. Então, o que se vê que uma extensa propriedade de terra não constitui um intitulamento se não aumentar o bem-estar das pessoas.

Presencia-se, então, que a análise seniana cumpre um papel importantíssimo no tocante às relações entre bens e serviços ambientais. 0 problema real que aparece na realidade social é que não há uma carência alimentar, mas sim uma dificuldade de acesso a estes alimentos, o que retém a capacidade de expansão das pessoas. Assim, a pobreza ocorre quando os indivíduos não têm condições de ter supridas suas necessidades básicas, tais como : alimentação, saúde, educação, isto é, quando as pessoas ficam privadas de suas capacitações fundamentais.

O problema evidenciado por Sen é que o acesso a bens e serviços ambientais é influenciado por uma série de elementos econômicos e legais, de modo que a pobreza não ocorre devido a quantidade de alimentos produzidos, mas as situações da fome são manifestadas devido a dificuldade de acesso a aquisição de alimentos ${ }^{34}$.

Desse modo, não é a escassez de bens e serviços que corrobora para a fome e a pobreza, porém os fatores determinantes para a miserabilidade é a incapacidade das de parcela da população em adquirir esses bens. Segundo Zanin, constam nos dados da Food and Agriculture Organization (FAO, Roma/Itália):

Estima que cada ano, cerca de um terço dos alimentos produzidos é perdido, notadamente nos países em

33 ZANIN, Gabriel. Abundância na produção e desperdício. In: Vitrini Agro. Revista Feed \& Food, São Paulo, 2014. Disponível em: http://www.feedfood.com.br/. Acesso em: 15 de jul. 2015, p. 40.

${ }^{34}$ SEN, Amartya. O desenvolvimento como liberdade. São Paulo: Companhia das Letras, 1999, p. 61. 
TONIOLO, Aline Dip. FRITZ, Karen Beltrame Becker. A adequação da concepção de intitulamentos para a apreciação de dotações e serviços ambientais. Revista Eletrônica Direito e Política, Programa de Pós-Graduação Stricto Sensu em Ciência Jurídica da UNIVALI, Itajaí, v.11, n.1, 10 quadrimestre de 2016. Disponível em: www.univali.br/direitoepolitica - ISSN 1980-7791.

desenvolvimento ( 1,3 bilhão de toneladas ou $U \$ \$ 680$ bilhões), durante a manipulação pós-colheita, processamento e armazenamento, enquanto o desperdício apurado na distribuição e consumo concentra-se nas regiões de elevada renda per capita do planeta (300 milhões de toneladas ou U\$\$310 bilhões), por causa dos excessivos padrões de qualidade que supervalorizam a aparência e outros atributos físicos, do abreviado prazo de validade, e do comportamento perdulário do consumidor na preparação de porções exageradas, cujas sobras são jogadas no lixo ${ }^{35}$.

Em virtude disso, esse problema antagônico resultante de haverem milhares de pessoas em situações que não são supridas suas capacitações básicas, isto é, o fato de haverem indivíduos em situação de fome afronta a segurança alimentar e afeta os estímulos para a inibição dos danos ambientais e reduz o acesso aos recursos disponíveis.

Neste seguimento, aponta os órgãos das Nações Unidas no seu relatório denominado Food Wastage Footprint publicado em 2013, que os resultados possibilitaram constatar que as implicações do desperdício corroboraram para "a emissão anual de 3 bilhões de toneladas de gases de efeito-estufa, atrás apenas das emissões totais de gás carbônico, equivalente as duas principais potências econômicas globais" ${ }^{\prime 36}$.

Assim, proteger o meio ambiente é fundamental para o bem estar das pessoas, razão pela qual as pessoas devem se conscientizar da importância de reduzir o desperdício de bens e serviços ambientais, pois os recursos naturais são limitados. À vista disso, o ecossistema ambiental favorece a melhoria na qualidade de vida dos agentes sociais, de modo que se este

${ }^{35}$ ZANIN, Gabriel. Abundância na produção e desperdício. In: Vitrini Agro. Revista Feed \& Food, São Paulo, 2014. Disponível em: http://www.feedfood.com.br/. Acesso em: 15 de jul. 2015, p. 40.

${ }^{36}$ ZANIN, Gabriel. Abundância na produção e desperdício. In: Vitrini Agro. Revista Feed \& Food, São Paulo, 2014. Disponível em: http://www.feedfood.com.br/. Acesso em: 15 de jul. 2015, p. 41. 
TONIOLO, Aline Dip. FRITZ, Karen Beltrame Becker. A adequação da concepção de intitulamentos para a apreciação de dotações e serviços ambientais. Revista Eletrônica Direito e Política, Programa de Pós-Graduação Stricto Sensu em Ciência Jurídica da UNIVALI, Itajaí, v.11, n.1, 10 quadrimestre de 2016. Disponível em: www.univali.br/direitoepolitica - ISSN 1980-7791.

bem tão precioso não for tutelado, haverá prejuízos nos serviços de transporte, provisão, purificação do ar e serviços culturais ${ }^{37}$.

Em decorrência disso, se forem lesados os serviços ambientais haverá um sério prejuízo as presentes e futuras gerações. Isto, se verificará porque os bens e serviços ambientais contribuem para o desenvolvimento da capacitação das pessoas e, muitas pessoas estão tendo suas capacitações básicas retidas por não conseguirem ter acesso a estes bens e serviços. Conforme Zanin, observa-se que:

A demanda contínua e crescente por alimentos até 2050, baseada principalmente na evolução demográfica (2,5 milhões de pessoas até 2060, US Census Bureau) e de renda na Ásia e na África (U\$ 25 trilhões de 2000 até 2030, IHS Global Insights), deflagrou em janeiro de 2013 a campanha "Think-Eat-Save: Reduce your feedprint", promovida pela FAO em conjunto com o Programa das Nações Unidas para 0 Meio Ambiente/PNUMA ${ }^{38}$.

Esta campanha visava alertar o grupo social acerca da escassez dos recursos naturais, almejando conscientizar as pessoas da importância de reduzir os desperdícios para preservar o meio ambiente e, contribuir para que haja uma produção e apropriação de alimentos de modo a possibilitar que mais indivíduos tenham acesso a bens e serviços ambientais e, em especial aos alimentos.

O resultado disto, levar-se-ia os agentes sociais a analisarem que a pobreza não se detém apenas ao aspecto financeiro e, sim a outros elementos, razão pela qual é de suma importância à visão multidimensional sobre a pobreza apresentada por Amartya Sen. Aliás, como é possível falar em

37 MILLENIUM ECOSYSTEMS ASSESSMENT. Ecosystem and human well-being: a framework for Assessment. 2005, p. 01. Disponível em: http://www.milleniumassessment.org. Acesso em: 13 ago. 2015.

${ }^{38}$ ZANIN, Gabriel. Abundância na produção e desperdício. In: Vitrini Agro. Revista Feed \& Food, São Paulo, 2014. Disponível em: http://www.feedfood.com.br/. Acesso em: 15 de jul. 2015, p. 41. 
TONIOLO, Aline Dip. FRITZ, Karen Beltrame Becker. A adequação da concepção de intitulamentos para a apreciação de dotações e serviços ambientais. Revista Eletrônica Direito e Política, Programa de Pós-Graduação Stricto Sensu em Ciência Jurídica da UNIVALI, Itajaí, v.11, n.1, $1^{\circ}$ quadrimestre de 2016. Disponível em: www.univali.br/direitoepolitica - ISSN 1980-7791.

bem-estar e expansão das capacitações das pessoas, se há miserabilidade e milhares de pessoas estão famintas?

Convém ressaltar, que o bem-estar humano é multidimensional e interfere em todas as suas dimensões. Nesta maneira, quando se aborda relações sociais, por exemplo, está dimensão interage com a dimensão das liberdades e oportunidade de escolha. Deste modo, o vínculo entre as questões ambientais e suas variantes com o bem-estar humano é muito complexo e diversificado.

Além disso, os bens e serviços ambientais são de suma relevância para a qualidade de vida das pessoas. Consoante a Avaliação do Milênio, observase a necessidade de haver uma distribuição igualitária e solidaria e bens e serviços ambientais para que os indivíduos possam expandir suas capacitações e fazer suas escolhas, melhorando seu bem-estar ${ }^{39}$.

No entanto, faz-se mister mencionar o papel das instituições no bem-estar humano, visto que formam um elo entre a questão ambiental e a dimensão humana. No entendimento de Rawls, "as instituições são um sistema público de regras que define cargos e posições com seus direitos e deveres, poderes e imunidades" ${ }^{\prime 40}$. Todavia, as instituições não se restringem apenas a um conjunto de regras, as instituição são a estrutura básica da sociedade.

Dessa forma, as instituições interferem na ideologia das pessoas, na condução de suas escolhas e oportunidades, razão pela qual assumem função de grande destaque quando o assunto é intitulamentos e dotações. Em seguida, é possível afirmar que "todos os indivíduos que estão nela engajados sabem o que saberiam se essas regras e a sua participação na atividade que elas definem fosse o resultado de um acordo" ${ }^{41}$.

39 MILLENIUM ECOSYSTEMS ASSESSMENT. Ecosystem and human well-being: a framework for Assessment. 2005, p. 01. Disponível em: http://www.milleniumassessment.org. Acesso em: 13 ago. 2015.

${ }^{40}$ RAWLS J. Uma Teoria Da Justiça. São Paulo; Martins fontes; 2000, p. 59.

${ }^{41}$ RAWLS J. Uma Teoria Da Justiça. São Paulo; Martins fontes; 2000, p. 60. 
TONIOLO, Aline Dip. FRITZ, Karen Beltrame Becker. A adequação da concepção de intitulamentos para a apreciação de dotações e serviços ambientais. Revista Eletrônica Direito e Política, Programa de Pós-Graduação Stricto Sensu em Ciência Jurídica da UNIVALI, Itajaí, v.11, n.1, $1^{0}$ quadrimestre de 2016. Disponível em: www.univali.br/direitoepolitica - ISSN 1980-7791.

Já Hodgson entende que as instituições impõem ordem a sociedade, estabelecendo a ordem nas ações e condutas humanas, sendo que o dinheiro, seria um exemplo de instituição. Todavia, as instituições institucionalizam hábitos entre as pessoas, como as estratégias e regras de conduta racionais. Assim, ao analisar ações permissíveis os agentes sociais têm oportunizados as suas possibilidades de escolhas ${ }^{42}$.

Neste ínterim, as instituições são importantíssimas para a capacitação dos indivíduos devido à dotação dos bens e serviços ambientais e na transformação de bens e serviços ambientais em intitulamentos. No tocante a dotação de bens e serviços ambientais, estes configuram-se como direitos reais de propriedade. De acordo com o entendimento de Machado:

O direito de propriedade foi apenas uma primeira geração de direitos fundamentais (o direito a liberdade), complementada por direitos de segunda geração ( direitos de igualdade, que inspiram a função social da propriedade) e de terceira geração (direitos de solidariedade, expressos no sentimento de que todos partilham de um futuro comum, o que inviabiliza a destruição, por exemplo, de uma floresta especialmente protegida, sob o argumento de que 0 direito de propriedade seria ilimitado $)^{43}$.

Em consequência disso, presencia-se que são os direitos de propriedade os responsáveis pelo ajuste e acesso dos indivíduos aos bens e serviços ambientais. Diante do exposto, constata-se que nem todos os bens e serviços ambientais podem contribuir para o bem-estar dos indivíduos e, muitos bens e serviços em razão das instituições podem acabar desempenhando funções diferentes, não visando à melhoria na qualidade de vida das pessoas.

\footnotetext{
${ }^{42}$ HODGSON, Geoffrey. The hidden persuaders: institutions and individuals in economic theory. Cambridge Journal of Economics, n. 27, 2003, p. 163.

${ }^{43}$ MACHADO, Antônio Claudio da Costa. Código Civil Interpretado. 4.Ed.-Barueri, São Paulo: Manole, 2011, p. 525.
} 
TONIOLO, Aline Dip. FRITZ, Karen Beltrame Becker. A adequação da concepção de intitulamentos para a apreciação de dotações e serviços ambientais. Revista Eletrônica Direito e Política, Programa de Pós-Graduação Stricto Sensu em Ciência Jurídica da UNIVALI, Itajaí, v.11, n.1, $1^{0}$ quadrimestre de 2016. Disponível em: www.univali.br/direitoepolitica - ISSN 1980-7791.

Contudo, as instituições interferem na exploração e apropriação de recursos naturais, denominados de dotação quando voltados ao bem-estar dos agentes sociais. Entretanto, para dar-se um intitulamento ambiental faz-se necessário que os bens e serviços ambientais sejam convertidos na capacitação das pessoas, almejando um avanço ou vantagem no cotidiano do grupo social.

Dessa maneira, a presente pesquisa buscou demonstrar a importância dos bens e serviços naturais serem utilizados em prol da expansão das capacitações dos indivíduos. Provavelmente, se haver a conscientização dos agentes sociais de que o meio ambiente é um direito do cidadão e, está intimamente relacionado com a expansão das possibilidades de escolhas dos indivíduos e seu bem-estar, será possível proteger a natureza e reduzir a miserabilidade do planeta.

\section{CONSIDERAÇÕES FINAIS}

O bem-estar humano sofre interferências diretas e indiretas do meio ambiente, em especial dos seus recursos. Todavia, os recursos naturais são limitados e escassos, o que consiste em uma ameaça à vida no planeta. Por esta razão, faz-se importante que haja uma mudança de atitudes dos agentes sociais, de modo a não tratar os recursos naturais apenas como bens comercializáveis.

A análise seniana, teoria desenvolvida por Amartya Sen, aborda a pobreza de uma forma multidimensional, mostrando que o fato de milhares de pessoas estarem famintas deve-se a dificuldade de acesso à aquisição de alimentos e, não a carência de alimentos. Consequentemente, nesta abordagem, a persistência de pessoa em situação de miserabilidade, compromete a expansão das possibilidades de escolha dos agentes sociais em prol do desenvolvimento humano. 
TONIOLO, Aline Dip. FRITZ, Karen Beltrame Becker. A adequação da concepção de intitulamentos para a apreciação de dotações e serviços ambientais. Revista Eletrônica Direito e Política, Programa de Pós-Graduação Stricto Sensu em Ciência Jurídica da UNIVALI, Itajaí, v.11, n.1, $1^{\circ}$ quadrimestre de 2016. Disponível em: www.univali.br/direitoepolitica - ISSN 1980-7791.

Em decorrência disso, os bens e serviços ambientais não corroborando para o bem-estar dos indivíduos, não é possível haver dotações e, muito menos intitulamentos, que permitir criar vínculos entre situações estruturais favoráveis ao aumento das capacitações dos seres humanos.

Além disso, verificou-se que as instituições regulam o elo entre os serviços ambientais e as variantes que interferem no bem-estar das pessoas. Entretanto, há uma desigual distribuição de bens e serviços ambientais entre o grupo social, de modo que algumas pessoas têm expandidas as suas possibilidades de escolha, expandindo suas capacitações.

Por outro lado, há milhares de pessoas que tem suas oportunidades e possiblidades de escolhas retidas. Assim, se não houver uma interferência das instituições almejando reduzir as desigualdades sociais e inibir a exploração desenfreada dos recursos naturais, o ser humano terá implicações na sua qualidade de vida, pois a natureza está dando sinais de exaustão.

Neste sentido, faz-se importante zelar pelo meio ambiente, direito fundamental do ser humano, patrimônio da humanidade, responsável pela satisfação das necessidades básicas dos indivíduos. Logo, se não haver um ambiente sadio e não forem contidas e reduzidas as desigualdades sociais, não é possível haver a expansão das capacitações das pessoas e, por conseguinte, a melhoria do seu bem-estar.

\section{REFERÊNCIAS CONSULTADAS}

ALVARengA, Paulo. Proteção jurídica do meio ambiente. São Paulo: Lemos e Cruz, 2005.

BRASIL, Vade Mecum Saraiva: obra coletiva de autoria da Editora Saraiva com a colaboração de Luiz Roberto Curia, Livia Céspedes e Juliana Nicoletti. 6. ed. atual. e ampl. São Paulo: Saraiva, 2014. 
TONIOLO, Aline Dip. FRITZ, Karen Beltrame Becker. A adequação da concepção de intitulamentos para a apreciação de dotações e serviços ambientais. Revista Eletrônica Direito e Política, Programa de Pós-Graduação Stricto Sensu em Ciência Jurídica da UNIVALI, Itajaí, v.11, n.1, $1^{\circ}$ quadrimestre de 2016. Disponível em: www.univali.br/direitoepolitica - ISSN 1980-7791.

CRUZ, Paulo Márcio. Da soberania à transnacionalidade: democracia, direito e estado no século XXI. Itajaí: Universidade do Vale do Itajaí, 2011.

DIAFÉRIA, Adriana. Desenvolvimento sustentável e o direito ao progresso científico, tecnológico e econômico: as oportunidades e as possibilidades de tutela. Meio ambiente, direito e biotecnologia: estudos em homenagem ao Prof. Dr. Paulo Affonso Leme Machado. Maria Auxiliadora Minahim, Tiago Batista Freitas, Thiago Pires Oliveira (coords.) Curitiba: Juruá, 2010.

FERRER, Gabriel Real. La construcción del Derecho Ambiental. Revista Aranzadi de Derecho Ambiental (Pamplona, España), no 1, 2002, p. 73-93.

FERNANDES, Márcio Borba. Termo de ajustamento de conduta ambiental e seus efeitos na responsabilização penal. In Temas Críticos em Direito. Organizadores: Alberto Wunderlich... [et al]. Guaiba: Sob Medida, 2012. v. 2.

HARVEY, David. Condição Pós- Moderna. 5. ed. São Paulo: Loyola, 1992.

HODGSON, Geoffrey. The hidden persuaders: institutions and individuals in economic theory. Cambridge Journal of Economics, $\mathrm{n}$. 27, p. 159-175, 2003.

IANNI, Octavio. A era do globalismo. 5. ed. - Rio de Janeiro: Civilização Brasileira, 2001.

MACHADO, Antônio Claudio da Costa. Código Civil Interpretado. 4.Ed.-Barueri, São Paulo: Manole, 2011.

MILARÉ, Édis. Direito do ambiente. 7. ed. São Paulo: Editora Revista dos Tribunais, 2012.

MILLENIUM ECOSYSTEMS ASSESSMENT. Ecosystem and human well-being: a

framework for Assessment. Disponível em: http://www.milleniumassessment.org. Acesso em: 13 ago. 2015.

RATTNER, Henrique. Liderança para uma sociedade sustentável. São Paulo: Nobel, 1999. 
TONIOLO, Aline Dip. FRITZ, Karen Beltrame Becker. A adequação da concepção de intitulamentos para a apreciação de dotações e serviços ambientais. Revista Eletrônica Direito e Política, Programa de Pós-Graduação Stricto Sensu em Ciência Jurídica da UNIVALI, Itajaí, v.11, n.1, $1^{0}$ quadrimestre de 2016. Disponível em: www.univali.br/direitoepolitica - ISSN 1980-7791.

RAWLS J. Uma Teoria Da Justiça. São Paulo; Martins fontes; 2000.

SARLET, Ingo Wolfgang. Dignidade da pessoa humana e direitos fundamentais na Constituição Federal de 1988. 2. ed. rev. amp. - Porto Alegre: Livraria do Advogado, 2002.

SEN, Amartya. Desigualdade Reexaminada. Rio de Janeiro: Record. 2001.

Companhia das Letras, 1999.

O desenvolvimento como liberdade. São Paulo:

O desenvolvimento como expansão das capacitações. Lua Nova: Revista de Cultura e Política. N. 28. São Paulo:CEDEC. 1993.

das Letras.1998.

Sobre ética e economia. São Paulo: Companhia .Ingredients of famine analysis: availability and entitlements. The Quarterly Journal of Economics, Aug, 1981. p. 433-464.

SIRVINSKAS, Luís Paulo. Manual de direito ambiental. 7. ed. rev. atual. e ampl. São Paulo: Saraiva, 2009.

ZANIN, Gabriel. Abundância na produção e desperdício. In: Vitrini Agro. Revista Feed \& Food, São Paulo, 2014. Disponível em: http://www.feedfood.com.br/. Acesso em: 15 de jul. 2015 